\title{
ALDEBARO KLAUTAU E O PROGRAMA DE MATEMÁTICAS DA ESCOLA NORMAL DE BELÉM (PARÁ) DE 1932
}

\author{
ALDEBARO KLAUTAU AND THE MATHEMATICS PROGRAM OF THE \\ NORMAL SCHOOL OF BELÉM (PARÁ) IN 1932
}

\section{Iran Abreu Mendes}

RESUMO: Neste artigo, caracteriza-se a expertise de Aldebaro Klautau acerca dos saberes matemáticos do primário (aritmética, geometria e desenho) no programa de matemáticas da Escola Normal de Belém durante o período em que nela atuou. Ao analisar os conteúdos dos documentos nos arquivos dessa escola, foram tomados os conceitos de expert, expertise e saberes profissionais docentes para refletir sobre a importância das conexões entre planejamento, metodologias e programa de ensino, na abordagem de saberes docentes relativos à matemática na formação de normalistas, que visa aprender a ensinar no curso primário.

Palavras-chave: Saberes docentes. Saberes matemáticos. Ensino primário. Escola Normal.

ABSTRACT: In this article, it is characterized the expertise of Aldebaro Klautau about the mathematical knowledge of the primary school (arithmetic, geometry, and drawing) in the mathematics program of the Normal School of Belém during the period when he worked there. When analyzing the contents of the documents in the archives of the school, the concepts of expert, expertise, and professional teaching knowledge were taken into consideration, in order to reflect on the importance of the connections between planning, methodologies, and teaching program, in the approach of teaching knowledge related to mathematics for the primary school teacher's formation. Keywords: Teaching knowledge. Mathematical knowledge. Primary school. Teacher training school.

\footnotetext{
1.Universidade Federal do Pará - Instituto de Educação Matemática e Científica - Programa de Pós-graduação em Educação em Ciências e Matemáticas - Belém (PA), Brasil.

*Autor correspondente: iamendes1@gmail.com

Número temático organizado por Wagner Rodrigues Valente
} 


\section{Introdução}

A Escola Normal de Belém foi fundada no dia 13 de abril de 1871, na gestão do então governador Joaquim Machado Portela. A escola é considerada a primeira instituição de ensino dessa natureza estabelecida no Pará e tinha a finalidade de oportunizar a profissionalização para o exercício do magistério no ensino primário da Instrução Pública no estado. Trata-se de uma instituição de formação de professores que teve suas atividades desenvolvidas por quase 150 anos, desde sua fundação. Foi, também, considerada por muitos anos a principal referência na formação de professores de nível médio do Pará. Tal escola tinha sede em Belém, uma vez que, durante muitas décadas, um quantitativo expressivo de alunos e alunas migravam do interior do estado para a capital na intenção de se formarem professores primários por meio dos estudos experienciados naquela escola.

Atualmente, 150 anos após sua fundação, funciona, nas antigas dependências da Escola Normal o Centro de Formação dos Profissionais da Educação Básica do Estado do Pará (CEFOR), administrado pelo Governo do Estado do Pará. O centro foi criado em 2014 pela Secretaria de Estado de Educação (SEDUC) com o objetivo de possibilitar aos educadores a apropriação das metodologias formativas e de transferência de tecnologias relativas ao ensino básico. No local, ainda se encontra parte do acervo documental da antiga Escola Normal de Belém, cuja documentação foi fundamental para analisar as relações entre saberes profissionais para ensinar matemática, documentos esses escritos pelo professor Aldebaro Cavalleiro de Macêdo Klautau.

Entre essa documentação, encontram-se livros sobre diversos assuntos relativos à educação em geral e a saberes específicos relacionados à formação de professores para o ensino primário. No acervo dos programas e guias de ensino, identificou-se um Plano de Ensino, Metodologia e Programa da Formação de Normalistas (KLAUTAU, 1932). O documento examinado contém um pequeno texto, que consideramos bastante provocador para reflexões sobre a compreensão das relações entre saberes profissionais para ensinar matemática. Tal documento também foi escrito pelo autor em estudo. Suas reflexões são potentes para um debate sobre a importância dos saberes docentes para inter-relacionar plano, metodologias e programa de ensino, na sustentação dos processos de ensino, que poderiam promover a aprendizagem dos estudantes normalistas em assuntos escolares, com implicações em seus modos de ensinar, posteriormente, no curso primário.

A partir de uma leitura inicial dos documentos, identificou-se a possibilidade de descrever, de maneira comentada, as sugestões e os encaminhamentos didáticos de Aldebaro Cavalleiro de Macêdo Klautau para as reflexões sobre planejamento e ação docentes ao abordar os saberes escolares para a formação de normalistas, o que foi materializado em seus escritos.

A intenção da pesquisa avançou um pouco mais na tentativa de investigar suas características intelectuais e profissionais, bem como suas ações políticas no sistema educacional da época. O objetivo era analisar o perfil do autor como especialista na formação de professores primários, além de seus modos de propor abordagens conceituais e didáticas para saberes escolares relacionados a aritmética, álgebra, geometria e desenho, conforme apresentado nos programas de ensino da escola citada no período em que o estudioso atuou na formação de normalistas.

Assim, o objetivo deste artigo é mostrar características da qualidade de expert em educação do professor em questão; ou seja, sua expertise no ensino de matemáticas, manifestada em sua trajetória docente na Escola Normal de Belém.

Para avançar nessa caracterização, tomaram-se como base as inflexões expostas por Bardin (2011) e Grawitz (1993) no tocante à relevância da análise de conteúdo a fim de descrever as informações identificadas nos documentos. Em seguida, inferiu-se acerca dos conhecimentos produzidos ou tomados, iniciando-se, 
após isso, a análise do material didático publicado e, posteriormente, estabelecendo interpretações com base nos conceitos de expert e expertise. Tais conceitos estão ligados à noção de saberes profissionais docentes, os quais podem ser descritos como saberes a ensinar e para ensinar. Isso porque, de acordo com as inflexões apontadas por Valente,

[...] o saber para ensinar matemática nos primeiros anos escolares envolve o domínio não só de algoritmos ligados às operações fundamentais da aritmética, ou mesmo conhecimento sobre geometria euclidiana. [...] Constitui-se a partir desse tempo como a ciência de formas intuitivas para a docência dos primeiros passos da aritmética e da geometria (VALENTE, 2017, p. 216).

Esse saber para ensinar faz parte dos saberes profissionais docentes, constituídos por meio de processos transformativos, nos quais há uma interdependência conectiva na formação e na ação profissional de um expert. Demanda-se, para isso, a apropriação e o processamento desses saberes profissionais (a ensinar e para ensinar), que tiveram implicações nos processos de disciplinação e disciplinarização, os quais impactaram o planejamento, os modos de ensinar (metodologias) e a organização dos saberes a ensinar (programas de ensino) na formação de professores primários nas escolas normais e na formação continuada desses professores após a conclusão de seus cursos normais.

Em um segundo momento, caracteriza-se o cenário da educação para a formação de normalistas no período que antecede as transformações no planejamento, no programa e nas metodologias de ensino na Escola Normal de Belém, a fim de situar a inserção de Aldebaro Klautau no contexto do ambiente de realização de suas atividades docentes. No terceiro momento, apresenta-se uma síntese biográfica do professor, de modo a mostrar seu itinerário intelectual e docente, que podem levar a considerá-lo um expert em educação, a partir dos conceitos estabelecidos em estudos sobre o tema. Avança-se, assim, nas reflexões sobre sua expertise, evidenciada em seus discursos e nos documentos cujos conteúdos foram analisados, visando compreender como está expressa essa expertise em termos de educação e ensino de matemáticas na formação de normalistas.

\section{Dos Conceitos de Experts e suas Expertises}

Para adentrar nas discussões acerca do tema central deste artigo, conforme anunciado, inicialmente será realizada uma reflexão sobre os conceitos expert e expertise, à luz de autores que discutem a correlação desses conceitos com o desenvolvimento de saberes profissionais docentes na formação de professores primários. Objetiva-se, com isso, relacionar esses saberes com o que Klautau compreende como a importância da imbricação entre plano, metodologia e programa de ensino. Ou seja, o autor visa a uma integração de saberes inerentes ao profissional que ensina. Aqui, trata-se da integração no sentido da indissociabilidade entre o saber a ensinar e o saber para ensinar pelo professor primário, ao menos no caso da aritmética, da geometria e do desenho.

Nesta parte do artigo, é importante destacar os significados atribuídos aos termos expert e expertise, uma vez que se trata de dois conceitos ligados ao processo histórico de disciplinarização das ciências da educação, especificamente em seu processo de avaliação da produção e do desenvolvimento de saberes profissionais a ensinar e para ensinar e em suas relações com a trajetória histórica da matemática escolar. Tais conceitos advêm do campo da filosofia, de origem francesa, expressando experiência, especialização e perícia, o que significa uma conjunção de competências, habilidades e conhecimentos geralmente demonstrados por uma pessoa a respeito de um sistema ou de uma tecnologia. 
Os termos citados são decisivos nas discussões relativas aos processos de transformação dos saberes profissionais docentes atuantes na educação pública do Pará na primeira metade do século XX. Assim, levaram-se em consideração as caracterizações que Hofstetter e Schneuwly (2017) imprimem a expert e expertise ao abordarem aspectos epistemológicos sobre a institucionalização do expert em educação nos séculos XIX e XX. Não se despreza, porém, o sentido atribuído por Coelho (2015), quando considera expertise o conhecimento adquirido com base no estudo de um assunto e a capacidade de aplicar tal conhecimento, resultando em experiência, prática e distinção naquele campo de atuação; ou seja, o termo se relaciona às habilidades e competências do indivíduo ou de indivíduos para executar algo.

Uma característica do expert é ser um profissional reconhecido como especialista em determinada área, destacando-se por sua destreza e sua competência na execução de um trabalho. Um expert é, portanto, uma pessoa versada no conhecimento de determinada coisa. É alguém com muita experiência e prática e, por isso, considerado apto a dar o seu parecer sobre determinado problema ou situação, com base nos seus conhecimentos. A esse respeito, destaca-se, aqui, que, de acordo com Jacques Chevallier (1996), há uma distinção entre o expert especialista e o expert generalista. O primeiro é quem possui conhecimento técnico e é recrutado de acordo com sua competência profissional. Já o segundo é capaz de ir além dos limites de sua expertise e produzir conhecimento prático sobre a sociedade. O uso de uma ou outra dessas figuras, que podem estar associadas aos próprios interesses de quem os convoca, tem base no conhecimento e no desempenho normativo esperado de cada expert.

Com base nas ponderações estabelecidas por Evers e Heijden (2017), considera-se que competência e conhecimento geralmente são usados de forma intercambiável para o mesmo atributo (psicológico) e que o significado dado à experiência refere-se a uma habilidade ou a um conhecimento especial adquirido por treinamento, estudos ou práticas, muitas vezes denominado formalmente por expressões como experiência profissional, ou a habilidade mais qualificada de uma pessoa de fazer algo. Nesse raciocínio, a expertise é admitida como habilidade em um campo específico, atribuída a alguém que é "experiente" e que tem ou exibe habilidades ou conhecimentos especiais derivados de preparação ou experiências. Outra especificação para expert é refletida como a forma com que se trata de alguém que adquiriu habilidade especial ou conhecimento de um assunto em particular; ou seja, alguém que seja autoridade no assunto.

Portanto, para encaminhar os procedimentos acerca desse movimento, que culminou na interpretação dos conteúdos, com base nos conceitos norteadores (expertise e expert, conectados aos saberes profissionais docentes), a fim de caracterizar o itinerário e as ações de Aldebaro Klautau na Escola Normal, esclarece-se que a descrição constituiu a primeira etapa, a qual conduziu à interpretação, que constituiu a última. Entre elas, porém, realizaram-se inferências que possibilitaram tornar explícitas algumas informações, as quais foram consideradas implícitas nos documentos, procurando sempre manter um equilíbrio na interpretação, apoiada no rigor estabelecido na pesquisa; ou seja, manter uma coerência entre o texto descrito e interpretado, com base nos conceitos que fundamentaram a interpretação.

Assim, procedeu-se à exploração, por meio de uma hipótese inicial, originada na primeira leitura dos documentos e em uma verificação interpretativa. Tal verificação foi pautada em uma leitura reflexiva e analítica, com base nos conceitos de expert e expertise, conectados à noção de saberes profissionais docentes, conforme já mencionado.

Entretanto, antes de abordar aspectos relacionados aos documentos examinados na pesquisa, considera-se necessário situar o momento em que ocorriam algumas alterações na Escola Normal. Além disso, também se julgou necessário analisar em que termos esse momento histórico influenciou na mudança do contexto daquela instituição de ensino e de que maneira o processo de disciplinarização requereu a presença de um perfil profissional docente como se evidencia sobre Aldebaro Kautau neste artigo. É nessa 
perspectiva que, na seção a seguir, trataremos de aspectos relativos às alterações estabelecidas nos programas de matemática da Escola Normal, a partir de 1924, até culminar na participação de um grupo de especialistas, entre os quais Klautau estava inserido.

\section{Um Cenário Forjado em Alterações no Curso Normal em 1924}

Nas primeiras décadas do século XX, a diminuição da extração e do comércio da matéria-prima advinda dos seringais da floresta impactou negativamente o contexto econômico da Amazônia, implicando diretamente no Pará. Em virtude das transformações sociais provenientes dessa situação, as criações de outras alternativas de mercado para as especiarias recém-descobertas na região mostraram-se como um potencial econômico que poderia diminuir tal crise.

Nessa perspectiva, embora não somente por esse motivo, as instituições de ensino precisaram se ajustar à situação e foram incorporadas novas alterações ao curso da Escola Normal, a partir do Decreto n. 4.049 (PARÁ, 1924), por meio do qual foi criado um novo regulamento de curso, assinado pelo governador do estado, Sousa Castro, cuja proposta de disciplinas relativas à matemática se manteve idêntica aos regulamentos anteriores; ou seja, duas disciplinas: matemática elementar (aritmética)/matemática elementar (álgebra e geometria); e desenho.

Além disso, havia uma proposta de disciplina de escritura mercantil, que talvez representasse a novidade acrescentada naquela alteração em virtude do contexto econômico e social do período. Isso porque o momento exigia um conhecimento maior dos professores sobre a situação relativa à inserção de saberes para uma formação também voltada à prática do comércio.

Embora não parecesse haver modificação no quadro dos programas de formação para o curso normal, ficou evidenciado que também se alterava, no programa, o modo de conduzir o ensino de saberes relativos à matemática, ensino esse no qual o docente deveria abordar o assunto sob o ponto de vista prático, pelas necessidades de uso cotidiano, sem deixar de considerar indispensável o desenvolvimento teórico. A proposta, naquele momento, era exercitar dois tipos de raciocínio dos alunos, o que caracterizava dois tipos de saberes: um teórico e outro prático, o que implicava relações entre saber, fazer, saber-fazer e como e por que saber-fazer.

Para os considerados experts no ensino de matemática na época, o raciocínio prático iniciaria logo no $1^{\circ}$ ano, havendo uma revisão dos estudos do curso primário, com ligeiros raciocínios, e do programa proposto para três anos do curso de matemática elementar (aritmética), o qual abrangeria os sistemas de numeração, especialmente o decimal, associado às operações sobre números inteiros, divisibilidade, máximo comum divisor, mínimo múltiplo comum e números primos. Em seguida, viria o aprendizado das frações e das operações sobre o tema e suas transformações, continuando com uma abordagem sobre metrologia (estudos sobre a organização e os métodos relativos ao sistema métrico decimal), especialmente sobre práticas relativas a esse sistema para o uso nas práticas comerciais (medida linear, de superfície, massa e volume e suas correlações).

Propunha-se, ainda, que se deveria abordar, posteriormente, noções sobre proporções, regra de três simples e composta, regras de companhia, juros, descontos e câmbio, também conectadas às práticas comerciais. Nessa parte, tratava-se da introdução dos conhecimentos sobre temas aritméticos relacionados ao comércio. A respeito dessas práticas, o programa enfatizava que se tratava de valorizar as aplicações da matéria estudada aos problemas da vida prática, ou seja, aproximar a aritmética de temas cotidianos dos alunos.

Sobre o ensino de matemática elementar (álgebra e geometria), o programa também permaneceu o mesmo, alterando apenas no tocante à distribuição dos assuntos ao longo dos anos do curso. Em álgebra, 
previa-se, no $1^{\circ}$ ano, o ensino de equações do primeiro grau e, em geometria, um estudo desde as noções básicas iniciais (pontos, retas, segmentos, relações métricas e planos) até áreas das figuras planas. No $2^{\circ}$ ano, depois da revisão dos assuntos tratados no $1^{\circ}$ ano, o professor deveria abordar, no ensino de álgebra, até equações biquadradas e, no de geometria, até área e volume da esfera, com ênfase principal nas atividades práticas, desafiando os alunos a exercícios frequentes que contemplassem questões de utilidade na vida cotidiana.

Com relação ao ensino de desenho, que seria oferecido nos três anos, o $1^{\circ}$ abordaria o desenho à mão livre, de ornatos simples, copiados de gesso conforme material disponível na escola. No $2^{\circ}$ ano, propunham-se exercícios práticos de composição geométrica e composições ornamentais à mão livre, de motivos do natural. Já no $3^{\circ}$ ano, haveria desenho à mão livre de figuras tanto naturais quanto de gesso e um complemento do estudo de composições ornamentais à mão livre. O professor deveria munir-se sempre, nos exercícios, de modelos, naturais ou não, para desenvolver o gosto artístico dos alunos até a estilização da flora amazônica.

Ainda com relação a aulas e exercícios práticos, abordados no capítulo V e em outros capítulos do regulamento, os artigos 43, 44 e 45 do decreto em questão mencionavam que esses seriam realizados no curso especial, sediado na escola anexa (práticas para a aprendizagem da docência), ${ }^{1}$ onde ocorreriam diariamente aulas práticas com a finalidade de desenvolver as aptidões didáticas do(a) futuro(a) professor(a). Essa escola era uma espécie de grupo escolar adjunto à Escola Normal, sob a inspeção do diretor dessa última, contendo as mesmas classes dos grupos escolares, com características de uma escola de aplicação. Essas práticas caracterizavam-se por atividades que, posteriormente, seriam incorporadas ao estágio supervisionado ou à prática de ensino do curso normal.

De acordo com o novo regimento, nessas aulas, os alunos normalistas deveriam ser divididos em turmas correspondentes ao número de classes da escola anexa, reservando-se para essa prática a hora final dos trabalhos letivos. Assim, estabelecia-se no documento que as aulas previstas seriam orientadas pelos professores da referida escola anexa, para a qual diariamente seriam selecionados alunos em número conveniente para a ocupação dos espaços, dispensando os demais alunos, que deveriam ser selecionados e inseridos na escola nos dias seguintes.

Portanto, cada turma de alunos do curso especial faria exercícios de docência em cada classe durante uma semana, preenchendo os turnos até o fim do ano letivo, cumpridas as instruções constantes no regimento que fosse organizado pela diretoria da Escola Normal. Nesses exercícios, os alunos deveriam agir de acordo com as práticas de aprendizagem da docência, participando ativamente delas, de modo que pudessem desenvolver ou adquirir suas aptidões para o exercício do magistério relativo ao ensino primário, habituando-se a utilizar seus conhecimentos e saberes apropriados para a formação fornecida pelas matérias escolares do curso normal.

Com base em informações mencionadas por Souza (1972), por volta de 1930, foi nomeado como diretor da Escola Normal o padre José Cupertino Contente, substituindo a antigo diretor, sr. Elias Augusto Tavares Vianna. Com essa mudança, ampliaram-se, nesse período, os avanços nas discussões sobre a proposição de diversos aspectos que operacionalizassem reformas no ensino da escola, entre as quais foram indicadas incorporações de princípios e métodos que, naquele momento, eram característicos das teorias propugnadas por Pestalozzi e Decroly.

Todavia, foi após quase dois anos de discussões que, em 1932, tais indicações passaram a ser incorporadas aos documentos relativos ao planejamento de ensino da escola. Nesse momento, foi organizado um grupo de intelectuais considerados detentores de conhecimentos suficientes para a implementação desses princípios e métodos em um documento oficial de planejamento de ensino para a Escola Normal. Esse grupo 
era composto pelos professores: Cornélio Pereira de Barros (português), Aldebaro Cavalleiro de Macêdo Klautau (matemáticas), Naide Vasconcellos (instrução moral e cívica), Manoel Lobato (história universal), Francisco Pondé (história natural), Elias Augusto Tavares Vianna (psicologia educacional), Waldemar Ribeiro (física), Bianor Penalber (higiene), João Paulo d’Albuquerque Maranhão (literatura).

É importante destacar que esse foi o grupo responsável pela elaboração do guia de orientação para planejamento e metodologias e programas de ensino para o uso na Escola Normal naquele momento. Além de exercer suas funções docentes nessa escola, o corpo docente supracitado exercia outras atividades profissionais das mais variadas, como redatores de jornais e revistas, em especial revistas pedagógicas, nas quais publicavam artigos, crônicas e orientações didáticas aos professores do ensino primário e do curso normal. Ocupavam, também, cargos administrativos em âmbito estadual e municipal, atuavam como políticos e, muitas vezes, em funções religiosas, ${ }^{2}$ como foi o caso de Aldebaro Klautau - que exerceu todas essas funções no estado, conforme será tratado na próxima seção deste artigo.

Como mencionado, a partir do trabalho realizado por esse grupo, foram concretizadas as modificações nos planos, nos programas e nas diretrizes metodológicas da Escola Normal, que ocasionaram a publicação de um guia intitulado Plano de Ensino. Methodologia e Programa das Cadeiras do $4^{\circ}$ Anno da Escola Normal (PARÁ, 1932).

É nesse guia que está descrita a expertise do Klautau em relação ao ensino das matemáticas na Escola Normal, quando ele próprio explicita suas maneiras de pensar e agir o fazer docente em relação a aritmética, álgebra, geometria e desenho para a formação de normalistas. Assim, na seção a seguir, serão apresentados alguns aspectos essenciais acerca do perfil biográfico de Aldebaro Klautau.

\section{À Guisa de uma Síntese Biográfica de um Expert}

O professor Aldebaro Cavalleiro de Macêdo Klautau nasceu na cidade de Belém (PA), em 2 de maio de 1902 (ou 1907) e faleceu também em Belém, em 8 de abril de 1983. Estudou no Colégio Nossa Senhora de Nazaré, sob orientação dos irmãos Maristas e fez o curso superior na Faculdade Livre de Direito do Pará. Tornou-se Bacharel em ciências jurídicas e sociais em 1929. Exerceu o magistério particular na Escola dos Padres Maristas e, em janeiro de 1929, foi nomeado professor de álgebra e geometria da Escola Normal do Pará.

Atuou como constituinte estadual de 1935 a 1947, liderando, na Assembleia do Estado, a minoria e, posteriormente, a maioria dos deputados. Foi membro da Ordem de Advogados do Brasil, secção do Pará, tendo presidido o respectivo conselho durante doze anos consecutivos. Foi presidente reeleito diversas vezes do Instituto dos Advogados do Pará, ocupando a cadeira de Inglês de Souza e exercendo o magistério superior como professor catedrático e emérito de direito penal da Universidade Federal do Pará, de 1953 a 1977, quando foi aposentado de forma compulsória. Nessa direção, seu itinerário intelectual evidencia suas vertentes de autor com prestações de numerosos e importantes livros sobre a Amazônia, trabalhos sobre fundamentos e princípios do direito, da religião, da defesa da democracia e de outros assuntos.

Na intenção de ampliar essa síntese biográfica, é importante também destacar que se trata de um intelectual que atuou em várias atividades profissionais, como advocacia, magistério e política, além de ter exercido funções administrativas na diretoria de empresas privadas na Amazônia, bem como atividades relacionadas a congregações religiosas - por exemplo a Conferência Nacional de Bispos do Brasil, de cuja Comissão de Justiça e Paz, no Brasil, filiada à Comissão Pontifica Justiça et Pax, com sede em Roma e criada pelo Papa Paulo VI, foi eleito membro.

A partir da forja do cenário da Escola Normal, entre 1924 e 1932, conjugada ao perfil biográfico de Aldebaro Klautau, será apresentada, a seguir, uma descrição interpretativa do plano, da metodologia e do 
programa de ensino da Escola, em 1932, estabelecidos pelo grupo de professores mencionados anteriormente, do qual emergiram as informações de interesse central deste artigo.

\section{Plano, Metodologia e Programa de Ensino da Escola em 1932}

Conforme foi mencionado anteriormente, a partir de meados da década de 1930, as ideias que passaram a predominar no exercício da docência na Escola Normal estavam fundamentadas em princípios inspirados em Pestalozzi, Decroly e, também, nas propostas de Lourenço Filho. Ao expressar reflexões sobre tais princípios educativos, os quais enunciavam o pensamento de Decroly como um sopro forte que abala, ainda hoje, a família didática, Loureiro (1934, p. 49-50) asseverava que adotar o seu método (de Decroly) significava a pretensão de antepor o amor à verdade ao instinto de conservação refletido pela escola tradicional.

Seguindo essa compreensão, Aldebaro Klautau (1932) afirmava que, em matemáticas, as fórmulas deveriam ser pessoais, deduzidas por meio da prática e do estudo consciente e metódico, caracterizando-se pela espontaneidade ou pelos desafios provocados, uma vez que o contato com as coisas estimula os sentidos das crianças e as impele a agir e a pensar.

Ao destacar que Decroly desenvolveu o "centro de interesse" em três fases (observação, associação e expressão), ampliando a segunda com exercícios de tecnologia e de associação de causas e efeitos, o guia discute aspectos relacionados a essas fases em "passos formais", enfatizando que esse processo havia sido desprezado pela Escola Nova Brasileira, que oferecia a lição como um todo, separando-a apenas por mero "expediente didático", em situação total, como uma atividade da classe e em contexto de globalização.

Nos trabalhos de observação, era enfatizada a importância de se levar a criança a familiarizar-se com os conhecimentos dos fenômenos, à investigação de causas e à observação de seus efeitos, uma vez que se tratava de uma prática que se imporia pelas vantagens facilmente auferidas. Assim, era nesses exercícios que o professor procuraria desenvolver, ainda, o vocabulário infantil, que ficaria mais conectado ao estudo da aritmética, da geometria e das lições de coisas.

Além disso, propugnava-se que a associação derivava da observação. Logo, ao serem orientados e controlados no uso da linguagem e nos conhecimentos adquiridos, os alunos poderiam exercitar diversas associações de ideias. Assim, o professor poderia apresentar aos alunos o conhecimento sob quatro enfoques:

a. Comparação de fatos e coisas com os de regiões distantes, encarados na atualidade, fazendo emergir a geografia ou a associação no espaço;

b. Explicação de fatos, colocando-os em relação ao fator tempo, ou seja, em comparação com os de épocas afastadas, fazendo surgir a história ou a associação no tempo;

c. Aplicações práticas e industriais das matérias primas, em relação às profissões que eram derivadas delas, pois assim fariam evidenciar as tecnologias;

d. Exercícios de investigações de causas e efeitos.

No desenvolvimento das aulas de associação, a criança poderia relacionar os novos conhecimentos aos adquiridos na fase da observação.

Assim, as orientações do guia destacam que o centro de interesse era o meio de levar a criança a mostrar o que aprendeu. Seriam nele incluídos os exercícios de linguagem oral e escrita, a ginástica, o desenho, os trabalhos manuais, as canções, entre outros, desde que relacionados a esse centro.

Em relação ao ensino de álgebra no $4^{\circ}$ ano no guia Plano de Ensino. Methodologia e Programa das Cadeiras do $4^{\circ}$ Anno da Escola Normal (KLAUTAU, 1932, p. 6-8), identificou-se que Aldebaro Klautau fez 
reflexões sobre a confecção de seus programas de ensino, enfatizando que se esforçava bastante para incluir neles as partes principais dos assuntos que pretendia abordar, embora, muitas vezes, deixasse de mencionar aspectos que considerava de caráter apenas informativo - geralmente apregoados como desnecessários de serem tratados nas aulas de matemática - ou sobre os modos de ensinar matemática. Explicava que fazia assim por considerar que tais assuntos não trariam vantagem nenhuma aos estudantes que pudesse fortalecer sua formação, tanto em conteúdo quanto em metodologia de ensino.

O professor informava, também, que, a esse respeito, procurava organizar o assunto de maneira que pudesse, ao mesmo tempo, ser totalmente ensinado no prazo previsto para alcançar o objetivo previsto e que, ainda, pudesse ser reorganizado pelas normalistas para seu exercício na escola anexa. Além disso, Klautau afirmava que, assim, sempre seria possível ficar disponível algum tempo para uma rápida revisão dos assuntos, pois também havia assunto em que a recapitulação não seria tão necessária.

Entretanto, a respeito de aritmética, álgebra e geometria, Klautau afirmava que as verdades tinham a necessidade de serem demonstradas, pois a demonstração é o método das matemáticas. Tal método consiste em uma operação pela qual se torna evidente uma proposição por meio de outra que seja evidente por si mesma ou já demonstrada; ou seja, uma verdade decorre de outra, essa de uma terceira e assim por diante, de modo que uma é a garantia da outra. Assim, o autor afirmava que a demonstração era um exercício de recordação incessante e exigia, para o alcance da aprendizagem, que o aluno estivesse sempre revendo as explicações recebidas do professor e exercitando-as.

Nesse sentido, Klautau esclarecia que, durante o ano letivo, em torno de três horas por semana destinadas ao ensino de cada cadeira (aritmética, álgebra ou geometria), ele empregava a primeira meia hora na arguição dos estudantes sobre o assunto tratado na aula anterior; reservava os trinta minutos restantes para abordar novos assuntos; e, ainda antes do final da aula, insistia em fazer perguntas sobre verdades já conhecidas e que, no momento, seriam tomadas como base para as verdades que deveriam ser demonstradas.

Igualmente, esclarecia sobre uma prática que realizava regularmente na forma de uma atividade quinzenal com os estudantes, na qual marcava os assuntos sobre os quais faria uma ligeira retomada em aulas anteriores à prova mensal. Ao comentar cada uma delas, mostrava aos alunos seus erros ou descuidos, de modo a estimulá-los ao cumprimento do dever.

Explicava que, no ensino de álgebra, a redução dos termos semelhantes representava o ponto de partida de todo o estudo do assunto, pois, a partir das noções preliminares da álgebra - que não era nada além de um método de simplificação e generalização aplicável a todas as matemáticas -, dava-se uma explicação clara e metódica da redução de termos semelhantes. Daí por diante, prosseguia na explicação do programa como um todo, conforme destacaremos a seguir. Informava, também, que abordava o assunto por meio de um estudo mais prático que teórico, não só por assim exigir a natureza da matéria, como para alcançar tudo no prazo de um ano disponibilizado para o ensino da álgebra.

No Programa de Matemática organizado por Aldebaro Klautau (1932), os assuntos centrais eram os seguintes: álgebra: noções preliminares; quantidades; valor numérico; adição, subtração, multiplicação e divisão algébricas; potenciação; fórmulas notáveis; divisibilidade por x, mais ou menos; MCD e MMC; frações algébricas; cálculo dos radicais; raiz quadrada; expoentes negativos e fracionários; imaginários; equação do primeiro grau; equações do segundo grau; desigualdades do primeiro grau; propriedades das raízes do segundo grau; equações biquadradas; trinômio do segundo grau.

As orientações sobre a abordagem do assunto constam no material que foi organizado e publicado em Belém do Pará em fevereiro de 1932, quando Aldebaro Cavalleiro de Macêdo Klautau era lente efetivo da Escola Normal e, nessa época, tinha 30 anos. Os livros adotados foram Curso superior de Álgebra e Álgebra de Serrasqueiro. 
Naquele período, firmou-se um rígido sistema de normatização da escola, por meio de regulamentos repressivos, impedindo inovações de cunho pedagógico baseadas nas ideias escolanovistas que circulavam em livros e artigos da época.

Em 1934, dois anos depois da reorganização do programa de ensino e das metodologias incorporadas e após a reforma do prédio onde funcionava o jornal A Província do Pará, o governo transferiu a Escola Normal para esse prédio, em frente à Praça da República, onde permaneceu até a criação do atual CEFOR, em 2014.

\section{Considerações Finais}

As informações identificadas e interpretadas à luz dos conceitos de expert e expertise, conectados aos conceitos de saberes profissionais docentes evidenciados pela participação de Aldebaro Klautau nas diversas atividades relacionadas à formação de professores primários na Escola Normal de Belém - com destaque para os anos em que atuou nessa escola (1929 a 1932) - levaram-nos a admitir sua potencialidade pedagógica para o ensino de matemáticas e sua expertise em relação ao trabalho docente de formação de professores primários, principalmente no que concerne ao domínio dos saberes elementares de aritmética a ensinar e para ensinar. Igualmente, as ações sociais e políticas relacionadas à educação no Pará, no período de 1929 a 1977, fortaleceram a interpretação de que Aldebaro Klautau possui características de um expert em educação.

Nesse sentido, o autor destacou-se pelas reflexões teórico-metodológicos sobre os saberes matemáticos a ensinar e para ensinar na formação de professores primários, bem como pelas contribuições para a organização do guia de planejamento, metodologias e programa de ensino, de cujo grupo elaborador fez parte.

Destaca-se aqui, também, que a realização da pesquisa nos documentos sobre a Escola Normal, embora de um acesso difícil, tornou possível compreender que Klautau constituiu um dos experts sobre os saberes elementares matemáticos que apresentaram orientações conceituais e pedagógicas para a formação de professores primários. Essas orientações eram voltadas para o ensino em sintonia com aquelas que estavam sinalizadas nos documentos oficiais educacionais e nas revistas pedagógicas do período pesquisado.

Outra conclusão relevante de mencionar é que, após uma reflexão sobre as fontes investigadas, tomando como base os conceitos de expert e expertise, bem como as ponderações de Valente (2017), foi possível compreender que os saberes para ensinar estavam mais evidentes nas propostas de Klautau, com potencialidades para sua inserção nos ambientes escolares, bem como que o professor em questão se mostrou um dos principais destaques nas produções dos textos de orientação para o ensino presentes nos programas de ensino e nas orientações metodológicas neles identificadas.

Igualmente, reiteramos a ideia de Certeau (1982), afiançando que o estudo realizado possibilitou compreender a importância das fontes históricas para conhecermos um pouco o passado. Podemos, assim, compreender os modos como os fatos ocorreram, sem inferir com base no presente, mas mostrando reflexões e interpretações acerca dos modos como os assuntos foram inseridos socialmente no contexto da formação de professores primários e, consequentemente, na instrução publica, por meio das ações docentes no ensino primário nos grupos escolares. Também é possível conhecer como esses assuntos implicaram atitudes, reorientações pedagógicas e reorganizações didáticas no currículo escolar para a escola e na sociedade paraense daquele período. 


\section{Notas}

1. Trata-se de um grupo escolar anexo à Escola Normal que funcionava como uma espécie de escola de aplicação para a formação experimental docente dos(as) normalistas.

2. Ver, de Almanak Laemmert, Administrativo, Mercantil e Industrial (RJ) - 1891 a 1940, disponível em: http://memoria. bn.br/DocReader/Hotpage/HotpageBN.aspx?bib=313394\&pagfis=90854\&url=http://memoria.bn.br/docreader. Acesso em: 20 out. 2020.

\section{REFERÊNCIAS}

BARDIN, L. Analise de conteúdo. Trad. Luís Antero Reto; Augusto Pinheiro. Lisboa: Edições 10, 2011.

BORER, V. L. Saberes: uma questão crucial para a institucionalização da formação de professores, In: HOFSTETTER, R.; VALENTE, W. R. (orgs.). Saberes em (trans)formação: tema central da formação de professores. São Paulo: Livraria da Física, 2017. p. 173-199. (Coleção Contextos da Ciência.)

CERTEAU, M. A escrita da história. Trad. Maria de Lourdes Menezes. Rev. tec. Arno Vogel. Rio de Janeiro: Forense Universitária, 1982.

CHEVALLIER, J. L’entrée en expertise. Politix, Paris, v. 9, n. 36, p. 33-50., 1996. (Usages sociaux des sciences sociales.)

COELHO, C. L. M. Avaliação, expertise e processos de decisão política: o programa Avaliação Externa das Escolas em Portugal (2006-2011). 2015. Tese (Doutorado em Ciências da Educação) - Faculdade de Psicologia e de Ciências da Educação, Universidade do Porto, Porto, 2015.

EVERS, A. T.; VAN DER HEIJDEN, B. I. J. M. Competence and professional expertise. In: MULDER, M.; WINTERTON, J. (eds.). Competence-based vocational and professional education. Cham: Springer, 2017.p. 83-101.

GRAWITZ, M. Méthodes des sciences sociales. 9. ed. Paris: Dalloz, 1993.

HOFSTETTER, R.; SCHNEUWLY, B. Saberes: um tema central para as profissões do ensino e da formação. In: HOFSTETTER, R.; VALENTE, W. R. (orgs.). Saberes em (trans)formação: tema central da formação de professores. São Paulo: Livraria da Física, 2017. p. 113-172. (Coleção contextos da Ciência.)

HOFSTETTER, R.; SCHNEUWLY, B.; FREYMOND, M. Penetrar na verdade da escolar para ter os elementos concretos de sua avaliação - A irresistível institucionalização de expert em educação (século XIX e XX). In: HOFSTETTER, R.; VALENTE, W. R. (orgs.). Saberes em (trans)formação: tema central da formação de professores. São Paulo: Livraria da Física, 2017a. p. 55-112. (Coleção Contextos da Ciência.)

HOFSTETTER, R.; SCHNEUWLY, B.; FREYMOND. M. Disciplinarização e disciplinação: as ciências da educação e as didáticas das disciplinas sob análise. In: HOFSTETTER, R.; VALENTE, W. R. (orgs.). Saberes em (trans)formação. Tema central da formação de professores. São Paulo: LF Editorial, 2017b.

KLAUTAU, A. C. M. Álgebra. In: Plano de Ensino, Methodologia e Programa das Cadeiras do $4^{\circ}$ Anno da Escola Normal. Belém: Officina Graphica do Instituto Dom Macedo Costa/Escola Profissional do Estado do Pará, 1932. p. 6-8. 
LOUREIRO, E. H. Do grupo escolar Rio Branco. Revista do Professorado, Belém, v. 1 n. 3, ago. 1934, p. 49-50.

PARÁ (Estado). Decreto n. 4049, de 9 de fevereiro de 1924. Regulamento da Escola Normal. Belém: Oficina Gráfica do Instituto Lauro Sodré, 1924.

PARÁ (Estado). Plano de Ensino. Methodologia e Programa das Cadeiras do $4^{\circ}$ Anno da Escola Normal. Belém: Officina Graphica do Instituto Dom Macedo Costa/Escola profissional do Estado do Pará, 1932.

PARÁ (Estado). Decreto n. XXX, de 25 de novembro de 1943. Belém: Officina Graphica do Instituto Lauro Sodré, 1943a.

PARÁ (Estado). Regulamento da Escola Normal de Belém. Belém: Officinas Graphicas do Instituto Lauro Sodré, 1943 b.

SOUZA, A. F. Apontamentos para a história do Instituto de Educação do Pará. Belém: Imprensa Oficial do Estado, 1972.

VALENTE, W. R. A matemática a ensinar e a matemática para ensinar: os saberes para a formação do educador matemático. In: HOFSTETTER, R.; VALENTE, W. R. Saberes em (trans)formação. Tema central da formação de professores. São Paulo: LF Editorial, 2017. 